\title{
Oral bioaccessibility tests to measure potentially toxic elements in inhalable particulate matter collected during routine air quality monitoring
}

\author{
Jawad Ali Hussein Alpofead, Christine M Davidson, David Littlejohn
}

WestCHEM, Department of Pure and Applied Chemistry, University of Strathclyde, 295 Cathedral Street, Glasgow G1 1XL, UK

\begin{abstract}
The simplified bioaccessibility extraction test (SBET) and the stomach phase of the unified bioaccessibility method (UBM) have been modified for use in assessing the bioaccessibility of potentially toxic elements in samples of $\mathrm{PM}_{10}$ collected during routine air quality monitoring. Arsenic, $\mathrm{Cd}, \mathrm{Cr}, \mathrm{Cu}, \mathrm{Fe}, \mathrm{Mn}, \mathrm{Ni}, \mathrm{Pb}$ and $\mathrm{Zn}$ were measured by inductively coupled plasma mass spectrometry in extracts of synthetic PM samples prepared by loading candidate soil reference material BGS102 onto TX40 (Teflon-coated borosilicate) filters widely used in standard commercial tapered element oscillating microbalance/filter dynamics measurement system (FDMS) ambient particulate monitors. Analysis of blanks revealed two important sources of contamination that had to be controlled in order to achieve reproducible results. The syringe filters used in the SBET released $\mathrm{Cu}$ and $\mathrm{Zn}$ into sample extracts during filtration and had to be washed with $80 \mathrm{~mL}$ of $0.4 \mathrm{M}$ glycine at $\mathrm{pH} 1.5$ immediately prior to use, whilst the FDMS filters used to collect $\mathrm{PM}_{10}$ were found to contain sufficient extractable $\mathrm{Zn}\left(\mathrm{ca} .3 \mu \mathrm{g} \mathrm{filter}^{-1}\right)$ to almost double the concentration released by the soil. The latter is a consequence of the use of $\mathrm{Zn}$ in filter manufacture and so could not be eliminated, but was successfully overcome by means of blank-subtraction. A ten-fold miniaturisation of the SBET and six-fold miniaturisation of the UBM allowed $0.1 \mathrm{~g}$ samples to be processed, with analyte recoveries generally within $\pm 10 \%$ of those obtained when the conventional procedures were used. Comparison between results obtained when the modified procedures were applied to soil alone, and when soil was loaded onto FDMS filters, indicated that the presence of the filter had no effect on extraction efficiency, except for Fe, provided blank-correction was performed. Results obtained for As, Cd and $\mathrm{Pb}$ with the modified UBM was applied to BGS102 on FDMS filters were $4.40 \pm 0.04,0.224 \pm 0.002$ and $17.3 \pm 0.8 \mathrm{mg} \mathrm{kg}^{-1}$, respectively $(\mathrm{n}=3)$, all within recommended ranges.
\end{abstract}

Keywords: Potentially toxic elements, inhaled particulate matter, oral bioaccessibility tests 


\section{Introduction}

Exposure to potentially toxic elements (PTE) associated with inhaled airborne particulate matter (PM) can cause adverse human health effects such as heart diseases and lung cancer. ${ }^{1,2}$ However not all PTE species present are equally labile and equally able to affect health. Therefore, measurement of total or pseudototal PTE concentrations in PM generally gives a poor indication of health risk. This has led to considerable current interest in the development of extraction procedures to determine the bioavailable or bioaccessible PTE fraction in PM. ${ }^{3,4}$ The bioavailable fraction can only be determined by using in-vivo methods, whilst in-vitro methods are used to measure the bioaccessible fraction. A more realistic risk assessment is achieved by applying in-vivo methods. However their disadvantages - such as high cost and the considerable lengths of time involved, together with ethical concerns mean that researchers have tended to focus on development or application of in-vitro methods. ${ }^{5,6}$

The aerodynamic diameter of airborne PM is between 0.005 and $100 \mu \mathrm{m},{ }^{7}$ but only the $\leq 10 \mu \mathrm{m}$ fraction $\left(\mathrm{PM}_{10}\right)$ is inhalable. ${ }^{8}$ Inhaled particles with diameter $<2.5 \mu \mathrm{m}\left(\mathrm{PM}_{2.5}\right)$ penetrate into the lungs, ${ }^{8}$ whilst particles between 2.5 and $10 \mu \mathrm{m}$ in diameter are transported from the conducting airways (nose, pharynx, larynx, trachea, bronchi and bronchioles) to the gastrointestinal tract by mucociliary clearance. ${ }^{8-10}$ Various synthetic lung fluids - notably Gamble's solution ${ }^{11}$ and modifications thereof ${ }^{12-18}$ have been proposed to estimate the fraction of PTE in $\mathrm{PM}_{10}$ that is bioaccessible following inhalation. However, because up to $99 \%$ of the $>2.5 \mu \mathrm{m}$ fraction of inhaled $\mathrm{PM}_{10}$ is eventually deposited in the gastrointestinal tract, ${ }^{19}$ oral bioaccessibility tests suitable for estimating the bioaccessibility of PTE associated with inhaled airborne particles are also required.

Several oral bioaccessibility tests have been described in literature for soil. Medlin ${ }^{4}$ produced the simplified bioaccessibility extraction test $(\mathrm{SBET})^{20}$ by modifying the physiologically based extraction test (PBET) of Ruby et al. ${ }^{21}$ to consider only the stomach phase and use a minimal number of reagents (glycine and $\mathrm{HCl}$ only). The SBET was validated for $\mathrm{Pb}$ by Ruby et al. ${ }^{22}$ using an in vivo swine study. A standard operating procedure was established by Dexler, ${ }^{4}$ the most recent version of which was published by the USEPA in $2012 .^{20}$ The bioaccessibility research group of Europe (BARGE) produced a more complex test, the unified bioaccessibility method (UBM), ${ }^{23}$ by modifying an in-vitro method originally created by researchers at the Netherlands National Institute for Public Health and the Environment. ${ }^{24}$ This test consists of two phases: the "stomach" phase (incorporating saliva and gastric fluids) and the "stomach and intestinal" phase (including duodenal and bile fluids). The UBM was evaluated by means of an international inter-laboratory exercise ${ }^{25}$ and validated ${ }^{26}$ for 
$\mathrm{As}, \mathrm{Cd}, \mathrm{Pb}$ and $\mathrm{Sb}$ in soils by conducting in-vivo swine studies. The validated BARGE UBM methodology was reported by British Geological Survey (BGS) in 2011. ${ }^{27}$ The similarity of the UBM extractants to body fluids and the fact that it has been validated for more than one element are key advantages of the method. However, the complexity of the extractants ( 24 chemicals) and lengthy time, both for the extraction ( $c a .4$ hours) and for preparation of reagents ( $c a .3$ hours) are serious drawbacks. Recently, the International Organization for Standardization ${ }^{28}$ recommended that bioaccessibility tests should address the exposure route that yields the maximum bioaccessible analyte concentration, to provide a conservative estimate of risk. For the UBM, this means that only the "stomach" phase generally needs be considered because lower values of bioaccessible PTE concentrations are usually obtained in the "stomach and intestinal" phase. . $^{2931}$

The $\mathrm{SBET}^{32-40}$ and the $\mathrm{UBM}^{6,28-31,39,41,42}$ have been employed to determine the bioaccessible PTE fraction in a variety of substrates, notably urban soils, ${ }^{29,30,32,34,41}$ soils impacted by mine waste or pesticides and herbicides, ${ }^{35-37,40}$ and street dust. ${ }^{38}$ There are few reports of the application of oral bioaccessibility tests to $\mathrm{PM}_{10}$, and none featuring the UBM. Madrid et al. ${ }^{32}$ used the SBET to extract PTE from the 2-10 $\mu \mathrm{m}$ particle size fractions of urban soils from Sevilla (Spain) and Torino (Italy) that had been obtained by fractionation of whole soil using a sedimentation method. Only Hu et al. ${ }^{43}$ have applied the SBET to genuine samples of urban airborne PM, collected on filters, in Nanjing (China). However, the fractions studied - total suspended particulates and $\mathrm{PM}_{2.5}$ - do not correspond to those transported to the gastrointenstinal tract by mucocillary clearance (hence use of an oral bioaccessability test is not optimal here) and their approach for sample collection - use of precombusted quartz microfibre filters and a large-volume air sampler - is not representative of that normally used in air quality monitoring. There remains a need to develop variants of soil-based oral bioaccessibility tests specifically optimised for application to samples of airborne particles routinely collected by governments and municipal authorities worldwide.

A common approach for continuous montoring of ambient airborne particular matter uses a tapered element oscillating microbalance (TEOM) and filter dynamics measurement system (FDMS) ${ }^{44,45}$ Air is drawn through a $\mathrm{PM}_{10}$ size-selective inlet, dried and directed to the mass transducer, where the decrease in oscillating frequency indicates the mass of material accumulated on the TEOM filter. ${ }^{46}$ In the FDMS, an alternative reference flow path incorporating a chiller unit and a $47 \mathrm{~mm}$ teflon-coated borosilicate TX40 filter ${ }^{47}$ is used to correct for loss of semi-volatile material. ${ }^{46}$ These TX40 filters are typically discarded after use, but represent a valuable source of real $\mathrm{PM}_{10}$ samples for chemical 
analysis, including the application of bioaccessibility tests.

The aim of the current study was to optimise versions of the SBET and UBM (stomach phase) suitable for use in the determination of bioaccessible PTE concentrations in $\mathrm{PM}_{10}$ supported on TX40 filters used in standard commercial TEOM/FDMS ambient particulate monitors. Specific objectives were:

(a) To modify the SBET and UBM (stomach phase) methods to make them more suitable for application to the small amount of $\mathrm{PM}_{10}$ typically collected, and

(b) To investigate the effects of the TX40 filter support on PTE concentrations and extraction efficiency using the SBET and UBM (stomach phase) methods.

\section{Experimental}

\subsection{Apparatus and Reagents}

Blank Pallflex TX40 FDMS filters were supplied by Air Monitors Ltd. (Gloucestershire, UK). These are composed of borosilicate microfibers reinforced with woven glass cloth and bonded with polytetrafluoroethylene (mass $5 \mathrm{mg} \mathrm{cm}^{-2}$, diameter $47 \mathrm{~mm}$ ). Acrodisc $\AA$ cellulose acetate membrane syringe filters (pore size $0.45 \mu \mathrm{m}$, diameter $25 \mathrm{~mm}$ ) were purchased from Sigma Aldrich (Gillingham, UK). The $\mathrm{pH}$ of solutions was measured by using a Mettler-Teledo (SevenGo ${ }^{\mathrm{TM}}$ ) $\mathrm{pH}$ meter. Suspensions were shaken and incubated by using an end-over-end rotator placed inside an incubator (Stuart ${ }^{\circledR}$ SI500 shaking incubator) manufactured by Barloworld Scientific Ltd., Staffordshire, UK. All chemicals were of analytical grade. Bovine serum albumen, $\mathrm{NaH}_{2} \mathrm{PO}_{4}, \mathrm{KCl}$, urea, $\mathrm{CaCl}_{2} .2 \mathrm{H}_{2} \mathrm{O}$, and pepsine (porcine) were purchased form Merck (Poole, UK). Glucose, $\mathrm{NaCl}, \mathrm{Na}_{2} \mathrm{SO}_{4}, \mathrm{NH}_{4} \mathrm{Cl}$, and $\mathrm{NaOH}$ were supplied by VWR International, Lutterworth, UK. Glucuronic acid, KSCN, glucosamine hydrochloride, alpha amylase, mucin (porcine), uric acid, hydrochloric acid ( $\mathrm{HCl})$ (36.5-38\%) and nitric acid $\left(\mathrm{HNO}_{3}\right)\left(\geq 69 \%\right.$ Trace SELECT ${ }^{\circledR}$ for trace analysis) were obtained from Sigma Aldrich (Gillingham, UK). Glycine was purchased from Fisher Scientific (Loughborough, UK). Multielement standard stock solution (10 $\mathrm{mg} \mathrm{L}^{-1}$ of $\mathrm{As}, \mathrm{Cd}, \mathrm{Cr}, \mathrm{Cu}, \mathrm{Mn}, \mathrm{Ni}, \mathrm{Pb}$, and $\mathrm{Zn}$ ) and $\mathrm{Fe}$ standard stock solution (1003 $\mathrm{mg} \mathrm{L}^{-1}$ ) were obtained from Qmx Laboratories, Essex, UK. All glassware and plastic ware were soaked overnight in $10 \% \mathrm{HNO}_{3}$ then rinsed three times with deionized water before use. 


\subsection{Simulation of $P M_{10}$ samples}

Since large quantities of $\mathrm{PM}_{10}$ with known concentrations of bioaccessible PTE were not available, a soil reference material (BGS102 from British Geological Survey, Keyworth, UK) was use in analytical method development. This material was chosen for several reasons. First, soil particles typically constitute a major component of airborne $\mathrm{PM}_{10}$. Second, it has a particle size distribution broadly similar to commercially available particulate matter CRMs (Table 1). Finally, it is the only reference material available that has target values for the bioaccessible concentration of $\mathrm{As}, \mathrm{Cd}$ and $\mathrm{Pb}$ using the UBM procedure and so could be used to assess the accuracy of the method developed. Airborne PM samples were simulated by smearing blank FDMS filters with $0.1 \mathrm{~g}$ of BGS102 using a plastic spatula.

\subsection{The original SBET and UBM (stomach phase) procedures}

When the $\mathrm{SBET}^{20}$ was applied, three $1.0 \mathrm{~g}$ test portions of soil BGS102 were placed into three 125 wide-mouth HDPE bottles, then $100 \mathrm{~mL}$ of glycine $\left(0.4 \mathrm{~mol} \mathrm{~L}^{-1}, \mathrm{pH} 1.5 \pm 0.05\right.$, pre-adjusted with $\mathrm{HCl}$ at $37 \pm 2{ }^{\circ} \mathrm{C}$ ) were transferred into each bottle. The bottles were tightly sealed, shaken by hand, then placed on an end-over-end shaker and rotated at $30 \pm 2 \mathrm{rpm}$ for 1 hour inside a pre-heated incubator at $37 \pm 2{ }^{\circ} \mathrm{C}$. At the end of the extraction, a $10 \mathrm{~mL}$ aliquot was removed from each bottle using a disposable $20 \mathrm{~cm}^{3}$ syringe, and filtered through a $0.45 \mu \mathrm{m}$ cellulose acetate acrodisc ${ }$ syringe filter. The $\mathrm{pH}$ of the mixture remaining in the extraction bottle was measured, and required to be $\mathrm{pH}$ $1.5 \pm 0.5$. Otherwise the extraction was repeated. Extracts were stored in polyethylene bottles at $4{ }^{\circ} \mathrm{C}$ prior to analysis by ICP-MS.

The validated BARGE UBM (stomach phase) methodology ${ }^{27}$ was adopted in this study. Three 0.6 $\mathrm{g}$ test portions of soil BGS102 were placed into three centrifuge tubes. A $9 \mathrm{~mL}$ aliquot of simulated saliva fluid was transferred to each tube and shaken by hand for 10 seconds. A $13.5 \mathrm{~mL}$ aliquot of simulated gastric fluid was then added to the tube. The $\mathrm{pH}$ was checked and, when necessary, adjusted to $1.2 \pm 0.05$ with $\mathrm{HCl}$ or $1 \mathrm{M} \mathrm{NaOH}$. The tubes were rotated inside a pre-heated incubator at $37 \pm 2{ }^{\circ} \mathrm{C}$ for 1 hour. At the end of the extraction, the $\mathrm{pH}$ of the suspensions obtained was checked to ensure it was less than $\mathrm{pH} 1.5$. Extracts then were centrifuged for 15 minutes at $4500 \mathrm{~g}$. A $2.5 \mathrm{~mL}$ aliquot of the supernatants were collected by pipetting and diluted 4-fold with $2 \% \mathrm{HNO}_{3}$. Extracts were stored in polyethylene bottles at $4{ }^{\circ} \mathrm{C}$ prior to analysis by ICP-MS. 

filters

\subsubsection{The modified SBET procedure}

The sample mass and extractant volume were each reduced ten-fold (to $0.1 \mathrm{~g}$ and $10 \mathrm{~mL}$ ) maintaining the same solid:solution ratio as in the original procedure. Three replicated extractions of soil BGS102 were carried out and results compared with those obtained using the original method (described in section 2.3).

Triplicate simulated PM samples were prepared by loading soil BGS102 onto FDMS filters as described in section 2.2, and the modified SBET was performed. A wide neck heavy-duty polypropylene bottle $(150 \mathrm{~mL})$ was used as the extraction vessel because the FDMS filter could be introduced flat (it was found that folding reduced the analyte extraction efficiency, presumably because of reduced contact between sample and extractant). The suspension obtained at the end of the extraction period was filtered through a pre-washed (see section 3.1 ) $\operatorname{acrodisc} \AA$ syringe filter to isolate the extract. Three $0.1 \mathrm{~g}$ test portions of soil BGS102 (not loaded on filters) and three blank FDMS filters were extracted in parallel to the three simulated $\mathrm{PM}_{10}$ samples.

\subsubsection{The modified UBM (stomach phase) procedure}

The sample mass and extractant volume were each reduced six-fold (to $0.1 \mathrm{~g}$ soil and a mixture containing $1.5 \mathrm{~mL}$ simulated saliva and $2.25 \mathrm{~mL}$ simulated gastric fluid). Three replicated extractions of soil BGS102 were carried out and results compared with those obtained using the original method (described in section 2.3).

Triplicate simulated PM samples were prepared by loading soil BGS102 onto FDMS filters as described in section 2.2, and the modified UBM (stomach phase) was performed. A wide neck heavy-duty polypropylene bottle $(150 \mathrm{~mL})$ was used as the extraction vessel, then the suspension obtained at the end of the extraction period was decanted into a $15 \mathrm{~mL}$ centrifuge tube for isolation of the extract by centrifugation. Although the volume of the vessel is adequate, low recoveries were obtained when the extraction was carried out directly in the $15 \mathrm{~mL}$ centrifuge tube (ranging from $17 \%$ for $\mathrm{Fe}$ to $48 \%$ for As relative to that obtained with the larger vessel). Because the extractant volume was small $(<4 \mathrm{~mL}) \mathrm{pH}$ adjustment was carried out using 25 or $50 \% v / v \mathrm{HCl}$ and $0.1 \mathrm{M} \mathrm{NaOH}$ and a micro $\mathrm{pH}$ electrode. Three $0.1 \mathrm{~g}$ test portions of soil BGS102 (not loaded on filters) and three blank FDMS filters were extracted in parallel to the three simulated $\mathrm{PM}_{10}$ samples. 


\subsection{Analyte quantification}

Extracts obtained were analysed by ICP-MS using an Agilent Model 7700x instrument (Agilent Technologies, Cheshire, UK). The operating conditions are shown in Table 2. To check for interferences, two or three isotopes were measured for each element, except for As and Mn which are monoisotopic. To remove spectroscopic interferences, a He collision cell was operated at a flow rate of $4.5 \mathrm{~L} \mathrm{~min}^{-1}$. Internal standards similar in mass to each isotope quantified were selected. Matrixmatched calibration standards were used. For quality control, one of the calibration standards was reanalysed every 10 analysis and again at the end of the sample run to checking for instrumental drift.

\subsection{Quality control}

No certified reference material is currently available for bioaccessible PTE in airborne PM. Analytical performance was therefore assessed by processing triplicate samples and by use of spike recovery tests. Extractants were spiked to known concentrations of analytes $\left(10020 \mu \mathrm{g} \mathrm{L}^{-1}\right.$ for Fe and $250 \mu \mathrm{g} \mathrm{L}^{-1}$ for other PTE), and taken through the complete extraction procedure. The percentage PTE spike recovery was calculated using equation 1.

$$
\% \text { spike recovery }=\left(\frac{\mid \text { measured conc. in spiked reagent }- \text { measured conc. } \text { in unspiked reagent } \mid}{\text { known conc. added }}\right) \times 100
$$

Equation 1

Approximately $92 \%$ of the RSD values for triplicate extractions were $<10 \%$, and the remaining RSDs were between 10 and $15 \%$ (except for one value of 24\%). The spike recoveries were between 86.8 and $114 \%$.

\section{Results and discussion}

\subsection{Washing regime to reduce $\mathrm{Cu}$ and $\mathrm{Zn}$ blanks arising from acrodisc ${ }^{\circledR}$ filters}

High concentrations of $\mathrm{Cu}\left(119 \mu \mathrm{g} \mathrm{L}^{-1}\right)$ and $\mathrm{Zn}\left(1520 \mu \mathrm{g} \mathrm{L}^{-1}\right)$ were initially found in procedural blanks from the SBET method, which caused poor precision (i.e. high RSD values) to be obtained for these analytes when replicate extractions were performed e.g. RSD of $9.2 \%$ for $\mathrm{Cu}$ and $78 \%$ for $\mathrm{Zn}$ $(n=3)$. The source was eventually identified as the acrodisc $\AA$ syringe filters used. This problem has not been highlighted in previous SBET studies ${ }^{34,37,38}$, perhaps because the method is most often applied to determine $\mathrm{As}$ and $\mathrm{Pb}$, and also due to the fact that some studies featuring $\mathrm{Cu}$ and $\mathrm{Zn}$ 
adopted centrifugation instead of filtration to obtain clear extracts for analysis. ${ }^{32}$ However, in a study using a US Pharmacopeia methodology to assess gastric bioaccessibility, Falta et al. ${ }^{48}$ noted that filtration, even using pre-cleaned cellulose acetate filters, led to higher blank levels than centrifugation of sample extracts.

To find a suitable washing regime, successive $10 \mathrm{~mL}$ aliquots of either glycine $\left(0.4 \mathrm{~mol} \mathrm{~L}^{-1}, \mathrm{pH}\right.$ 1.5), $\mathrm{HCl}(\mathrm{pH} 1.5)$ or deionized water were passed through three new acrodisc ${ }^{\circledR}$ filters and the filtrates analysed using ICP-MS. The filtrates obtained using deionised water did not contain $\mathrm{Cu}$ or $\mathrm{Zn}$ at detectable concentrations but, as shown in Fig. 1, the other reagents were able to leach these analytes from the syringe filters. The concentrations of $\mathrm{Cu}$ and $\mathrm{Zn}$ decreased markedly with increased volume of washing solution. After $80 \mathrm{~mL}$ of glycine or $\mathrm{HCl}$ had been passed through, the concentrations of $\mathrm{Cu}$ in the filtrates were 0.217 and $0.154 \mu \mathrm{g} \mathrm{L}{ }^{1}$, respectively, and 38.9 and $29.2 \mu \mathrm{g}$ $\mathrm{L}^{-1}$, respectively, for $\mathrm{Zn}$. These values did not change significantly on further washing. Although both glycine and $\mathrm{HCl}$ were able successfully to remove the $\mathrm{Cu}$ and $\mathrm{Zn}$ contribution to the procedural blank arising from the syringe filters, washing with glycine $(4 \times 20 \mathrm{~mL})$ was chosen because glycine is used as extractant in the SBET. It is important to note that the entire washing regime had to be carried out immediately prior to use of the filter. If filters were washed and then left to stand for a period as short as 20 minutes before use, then the blank concentrations of, especially, $\mathrm{Zn}$ increased markedly as additional contaminant leached out of the filter.

\subsection{Modification of the SBET and UBM (stomach phase)}

Results obtained for the original and modified SBET and UBM (stomach phase) methods are presented in Table 3. It can be seen that the concentrations of PTE extracted by the modified methods are similar to those obtained with the original methods, with recoveries $100 \pm 10 \%$ for the modified SBET (except for Fe and $\mathrm{Pb}$, where values of 119 and 115\% were obtained) and $100 \pm 4 \%$ for the modified UBM. The student t-test (at 0.05 significance level) indicated that there was no significant difference between the results obtained using original and modified SBET for all PTE studied whereas, for the UBM (stomach phase), the t-test passed for $\mathrm{As}, \mathrm{Cd}, \mathrm{Cu}, \mathrm{Fe}$ and $\mathrm{Pb}$, but failed for $\mathrm{Cr}$, $\mathrm{Mn}, \mathrm{Ni}$, and $\mathrm{Zn}$. However, the relative percentage difference (\%RDP) was low $(<4.4 \%)$ for all analytes (see Table 3) using the UBM.

The bioaccessible $\mathrm{As}, \mathrm{Cd}$, and $\mathrm{Pb}$ concentrations in the UBM (stomach phase) were within the certified and guideline values $^{23}$ of $4.52 \pm 1.28,0.281 \pm 0.170$, and $13.0 \pm 6.0 \mathrm{mg} \mathrm{kg}^{-1}$, respectively, in 
both original or modified versions of the procedure. Unfortunately, no indicative values are available for analytes extractable from BGS102 using the SBET.

Different concentrations of PTE were extracted by the UBM (stomach phase) and SBET procedures, using either the original or the modified methods. Differences between extractable analyte concentrations obtained using different oral bioaccessibility tests have been noted in previous studies, for example reference. ${ }^{49}$ This is to be expected based on the different reagents employed (for example the presence of mucin in the UBM has been reported to increase the bioaccessible concentration of $\mathrm{Cr}, \mathrm{Cu}, \mathrm{Ni}, \mathrm{Pb}$, and $\mathrm{Zn}^{28}$ ) and $\mathrm{pH}$ values at which extractions are performed. The $\mathrm{pH}$ has been reported to be a dominant factor that affects the solubility of elements in oral bioaccessibility tests ${ }^{50}$ and is likely to be responsible for the differences observed in the current study, where the UBM ( $\mathrm{pH}$ 1.2) generally yielded higher bioaccessible analyte concentrations than the SBET (pH 1.5).

\subsection{Contribution of blank FDMS filters to measured bioaccessible PTE content}

The concentrations of PTE extracted when the modified SBET and UBM (stomach phase) were applied to blank FDMS filters are presented in Table 4. The concentrations were generally low often less than limits of detection - with the notable exception of $\mathrm{Zn}$. The presence of the FDMS filter contributed a significant $\mathrm{Zn}$ bank to the analysis. Each filter released around $3 \mu \mathrm{g}$ of $\mathrm{Zn}$, which was similar to the amount released by the soil sample itself (assuming $0.1 \mathrm{~g}$ of soil, containing $35 \mathrm{mg}$ $\mathrm{kg}^{-1}$ extractable $\mathrm{Zn}$, had been loaded). This contamination cannot easily be eliminated because $\mathrm{Zn}$ is an intrinsic component of the FDMS filters, added as a binder during the production process. ${ }^{51}$ Fortunately, the between-filter variability in extractable $\mathrm{Zn}$ concentrations was found to be relatively low $(<19 \%$ for the SBET and $<9 \%$ for the UBM, $n=3)$ and it is therefore feasible to blank-correct results obtained by extracting a (set of) blank filter(s) in parallel with samples. All subsequent results were therefore corrected for filter blanks for all PTE tested.

\subsection{Application of the modified SBET and UBM (stomach phase) to simulated PM samples}

Fig 2 compares the bioaccessible concentrations of PTE in soil BGS102 alone (bars SBET 1 and UBM 1) with results obtained when the soil was smeared onto FDMS filters to simulate $\mathrm{PM}_{10}$ samples (bars SBET 2 and UBM 2) for both modified oral bioaccessibility tests. The presence of the FDMS filter did not appear to affect the bioaccessible concentrations measured in either case. This was confirmed using t-tests at 0.05 significance level (see Table 5) where neither method showed a 
significant difference obtained between results for soil alone and for soil presented on a filter, except for Fe. Relative percentage difference (RDP) values between soil alone and soil on a filter were $<2 \%$ for the modified SBET method, except for Zn (10.2\%) and $<5 \%$ for the modified UBM (stomach phase) except for $\mathrm{Ni}$ and $\mathrm{Pb}$ (11.7 and 6.2\%, respectively).

Results obtained when the modified UBM (stomach phase) extraction was applied to BGS102 smeared on a FDM filter to simulated $\mathrm{PM}_{10}$ were $4.40 \pm 0.04 \mathrm{mg} \mathrm{kg}^{-1}$ for As, $0.224 \pm 0.002 \mathrm{mg} \mathrm{kg}^{-1}$ for $\mathrm{Cd}$, and $17.3 \pm 0.8 \mathrm{mg} \mathrm{kg}^{-1}$ for $\mathrm{Pb}$, all within recommended ranges.

\section{Conclusion}

Two oral bioaccessibility methods have been successfully modified and applied to synthetic PM samples supported on TX40 filters used in standard TEOM/FDMS ambient particulate monitors worldwide. The study highlighted the importance of filter blanks. Thorough washing of acrodisc $\mathbb{R}$ syringe filters with $80 \mathrm{~mL}$ of acidified glycine solution immediately before use was required to minimised blank levels of $\mathrm{Cu}$ and $\mathrm{Zn}$ in the SBET. Analysis of blank FDMS filters revealed that, whilst the reagents used in both oral bioaccessibility tests extracted minimal concentrations of most PTE from the filter medium, levels of extractable $\mathrm{Zn}$ were significant. The latter is a consequence of the use of $\mathrm{Zn}$ in filter manufacture and so could not be eliminated, but was successfully overcome by means of blank-subtraction. The extractability of PTE from the test substrate was not affected by 10 fold miniaturisation of the SBET or by 6-fold miniaturisation of the UBM, nor by the presence of the FDMS filters provided blank-correction was performed. The methods developed are therefore suitable for application to real samples of inhalable airborne PM collected during routine air quality monitoring campaigns.

\section{Acknowledgement}

JA acknowledges financial support from the Iraqi Ministry of Higher Education and Scientific Research and the Iraqi Ministry of Education. 
1. A. Valavanidis, K. Fiotakis and T. Vlachogianni, Journal of Environmental Science and Health. Part C, Environmental carcinogenesis \& ecotoxicology reviews, 2008, 26, 339-362.

2. L. Ferreira-Baptista and E. De Miguel, Atmospheric Environment, 2005, 39, 4501-4512.

3. S. W. Casteel, C. P. Weis, G. M. Henningsen and W. J. Brattin, Environmental Health Perspectives, 2006, 114, 1162-1171.

4. J. Wragg and M. Cave, In-vitro Methods for the Measurement of the Oral Bioaccessibility of Selected Metals and Metalloids in Soils: A Critical Review, Report P5-062/TR/01, Environment Agency, UK, 2003.

5. G. Schoeters, Journal of Toxicology and Environmental Health, Part B: Critical Reviews, 2010, 13, 232-241.

6. J. Wragg and M. Cave, Analytica Chimica Acta, 2012, 722, 43-54.

7. Health effects institute (HEI), Understanding the health effects of components of the particulate matter mix: progress and next steps., Health effects institute, 2002.

8. N. Shah, V. Shah and N. Chivate, Journal of Applied Pharmaceutical Science 2012, 02, 3337.

9. M. King, in Physiologic basis of respiratory disease, BC Decker Inc, USA, 2005, ch. 35, pp. 409-416.

10. R. Tarran, Proceedings of the American Thoracic Society, 2004, 1, 42-46.

11. O. R. Moss, Health Physics, 1979, 36, 447-448.

12. M. Takaya, Y. Shinohara, F. Serita, M. Ono-Ogasawara, N. Otaki, T. Toya, A. Takata, K. Yoshida and N. Kohyama, Industrial Health, 2006, 44, 639-644.

13. A. E. Taunton, M. E. Gunter, G. K. Druschel and S. A. Wood, American Mineralogist, 2010, 95, 1624-1635.

14. W. Stopford, J. Turner, D. Cappellini and T. Brock, Journal of Environmental Monitoring, 2003, 5, 675 .

15. J. Wragg and B. Klinck, Journal of Environmental Science and Health, Part A:

Toxic/Hazardous Substances and Environmental Engineering, 2007, 42, 1223-1231.

16. J. E. Gray, G. S. Plumlee, S. A. Morman, P. L. Higueras, J. G. Crock, H. A. Lowers and M. L. Witten, Environmental Science \& Technology, 2010, 44, 4782-4788.

17. C. Julien, P. Esperanza, M. Bruno and L. Y. Alleman, Journal of Environmental Monitoring, 2011, 13, 621-630.

18. N. Boisa, N. Elom, J. R. Dean, M. E. Deary, G. Bird and J. A. Entwistle, Environment International, 2014, 70, 132-142.

19. R. Martin, K. Dowling, D. Pearce, J. Sillitoe and S. Florentine, Geosciences, 2014, 4, 128175.

20. E. P. A. USA, Standard Operating Procedure for an In Vitro Bioaccessibility Assay for Lead in Soil, Report 9200.2-86, Enironmental Agency, USA, 2012. 
21. M. V. Ruby, A. Davis, T. E. Link, R. Schoof, R. L. Chaney, G. B. Freeman and P. Bergstrom, Environmental Science \& Technology, 1993, 27, 2870-2877.

22. M. V. Ruby, R. Schoof, W. Brattin, M. Goldade, G. Post, M. Harnois, D. E. Mosby, S. W. Casteel, W. Berti, M. Carpenter, D. Edwards, D. Cragin and W. Chappell, Environmental Science \& Technology, 1999, 33, 3697-3705.

23. J. Wragg, M. Cave, N. Basta, E. Brandon, S. Casteel, S. Denys, C. Gron, A. Oomen, K. Reimer, K. Tack and T. Van de Wiele, Science of the Total Environment, 2011, 409, 40164030 .

24. A. G. Oomen, C. J. M. Rompelberg, M. A. Bruil, C. J. G. Dobbe, D. Pereboom and A. Sips, Archives of Environmental Contamination and Toxicology, 2003, 44, 281-287.

25. M. Cave, J. Wragg, H. Taylor, N. Basta, E. Brandon, S. Casteel, C. Gron, A. Oomen, and T. Van de Wiele, Inter-laboratory Trial of a Unified Bioaccessibility Procedure, Report Open report OR/07/027, British Geological Survey, Nottingham, 2009.

26. S. Denys, J. Caboche, K. Tack, G. Rychen, J. Wragg, M. Cave, C. Jondreville and C. Feidt, Environmental Science \& Technology, 2012, 46, 6252-6260.

27. BARGE and INERIS, UBM procedure for the measurement of inorganic contaminant bioaccessibility from solid matrices, http://www.bgs.ac.uk/barge/docs/BARGE_UBM_DEC_2010.pdf, (accessed 2014).

28. M. Rosende, L. M. Magalhaes, M. A. Segundo and M. Miro, Analytica Chimica Acta, 2014, 842, $1-10$.

29. A. Broadway, M. Cave, J. Wragg, F. M. Fordyce, R. J. F. Bewley, M. C. Graham, B. T. Ngwenya and J. G. Farmer, Science of the Total Environment, 2010, 409, 267-277.

30. H. Roussel, C. Waterlot, A. Pelfrene, C. Pruvot, M. Mazzuca and F. Douay, Archives of Environmental Contamination and Toxicology, 2010, 58, 945-954.

31. A. Barsby, J. M. McKinley, U. Ofterdinger, M. Young, M. Cave and J. Wragg, Science of the Total Environment, 2012, 433, 398-417.

32. F. Madrid, M. Biasioli and F. Ajmone-Marsan, Archives of environmental contamination and toxicology, 2008, 55, 21-32.

33. S. Das, J. S. Jean and S. Kar, Ecotoxicology and Environmental Safety, 2013, 92, 252-257

34. S. M. Rodrigues, N. Cruz, C. Coelho, B. Henriques, L. Carvalho, A. C. Duarte, E. Pereira and P. F. Romkens, Environmental pollution, 2013, 183, 234-242.

35. J. Li, Y. Wei, L. Zhao, J. Zhang, Y. Shangguan, F. Li and H. Hou, Ecotoxicology and Environmental Safety, 2014, 110, 308-315.

36. J. Y. Kim, K. W. Kim, J. U. Lee, J. S. Lee and J. Cook, Environmental Geochemistry and Health, 2002, 24, 215-227.

37. S. W. Lee, B. T. Lee, J. Y. Kim, K. W. Kim and J. S. Lee, Environmental Monitoring and Assessment, 2006, 119, 233-244.

38. B. Yu, Y. Wang and Q. Zhou, PLOS One, 2014, 9, 9.

39. N. Cruz, S. M. Rodrigues, D. Tavares, R. J. Monteiro, L. Carvalho, T. Trindade, A. C. Duarte, E. Pereira and P. F. Romkens, Chemosphere, 2015, 135, 304-311.

40. A. L. Juhasz, E. Smith, J. Weber, M. Rees, A. Rofe, T. Kuchel, L. Sansom and R. Naidu, Chemosphere, 2007, 69, 69-78. 
41. J. G. Farmer, A. Broadway, M. Cave, J. Wragg, F. M. Fordyce, M. C. Graham, B. T. Ngwenya and R. J. Bewley, The Science of the Total Environment, 2011, 409, 4958-4965.

42. A. L. Juhasz, E. Smith, J. Weber, M. Rees, T. Kuchel, A. Rofe, L. Sansom and R. Naidu, Journal of Environmental Science and Health, Part A: Toxic/Hazardous Substances and Environmental Engineering, 2013, 48, 604-611.

43. X. Hu, Y. Zhang, Z. Ding, T. Wang, H. Lian, Y. Sun and J. Wu, Atmospheric Environment, 2012, 57, 146-152.

44. P. Lawson and S. Tellis, Personal communication. Air Monitors Ltd, UK, 2015.

45. O. Butler, Personal communication. Health and Safety Laboratory, UK, 2015.

46. Thermo Fisher Scientific, Operating guide for TEOM-FDMS 1405-F ambient particulate monitor, http://www.thermoscientific.com/content/dam/tfs/ATG/EPD/EPD

Documents/Product Manuals \& Specifications/Air Quality Instruments and Systems/Particulate/EPM-manual-1405F.pdf, (accessed 2014).

47. Pall Life Sciences, Filtration products for air monitoring and sampling, http://www.pall.com/pdfs/Laboratory/08.1868 Air Monitoring SS.pdf, (accessed 2014).

48. T. Falta, A. Limbeck, G. Koellensperger and S. Hann, Analytical and Bioanalytical Chemistry, 2008, 390, 1149-1157.

49. A. G. Oomen, A. Hack, M. Minekus, E. Zeijdner, C. Cornelis, G. Schoeters, W. Verstraete, T. Van de Wiele, J. Wragg, C. J. M. Rompelberg, A. Sips and J. H. Van Wijnen, Environmental Science \& Technology, 2002, 36, 3326-3334.

50. A. L. Juhasz, J. Weber, E. Smith, R. Naidu, M. Rees, A. Rofe, T. Kuchel and L. Sansom, Environmental Science \& Technology, 2009, 43, 9487-9494.

51. S. Tellis, Personal communication. Air Monitors Ltd, UK, 2015. 


\section{Legends for Figures}

Figure 1

Release of $\mathrm{Cu}$ and $\mathrm{Zn}$ from blank acrodisc ${ }^{\circledR}$ syringe filters washed with glycine $\left(0.4 \mathrm{~mol} \mathrm{~L}^{-1} \mathrm{pH} 1.5\right)$ or $\mathrm{HCl}(\mathrm{pH} 1.5)$

\section{Figure 2}

The bioaccessible concentrations of potentially toxic elements in soil BGS102 (1)

alone and (2) when smeared on FDMS filters to simulated $\mathrm{PM}_{10}$ samples, as obtained with the modified simplified bioaccessibility extraction test (SBET) and stomach phase of the unified bioaccessibility method (UBM); error bars represent one standard deviations $(n=3)$ 

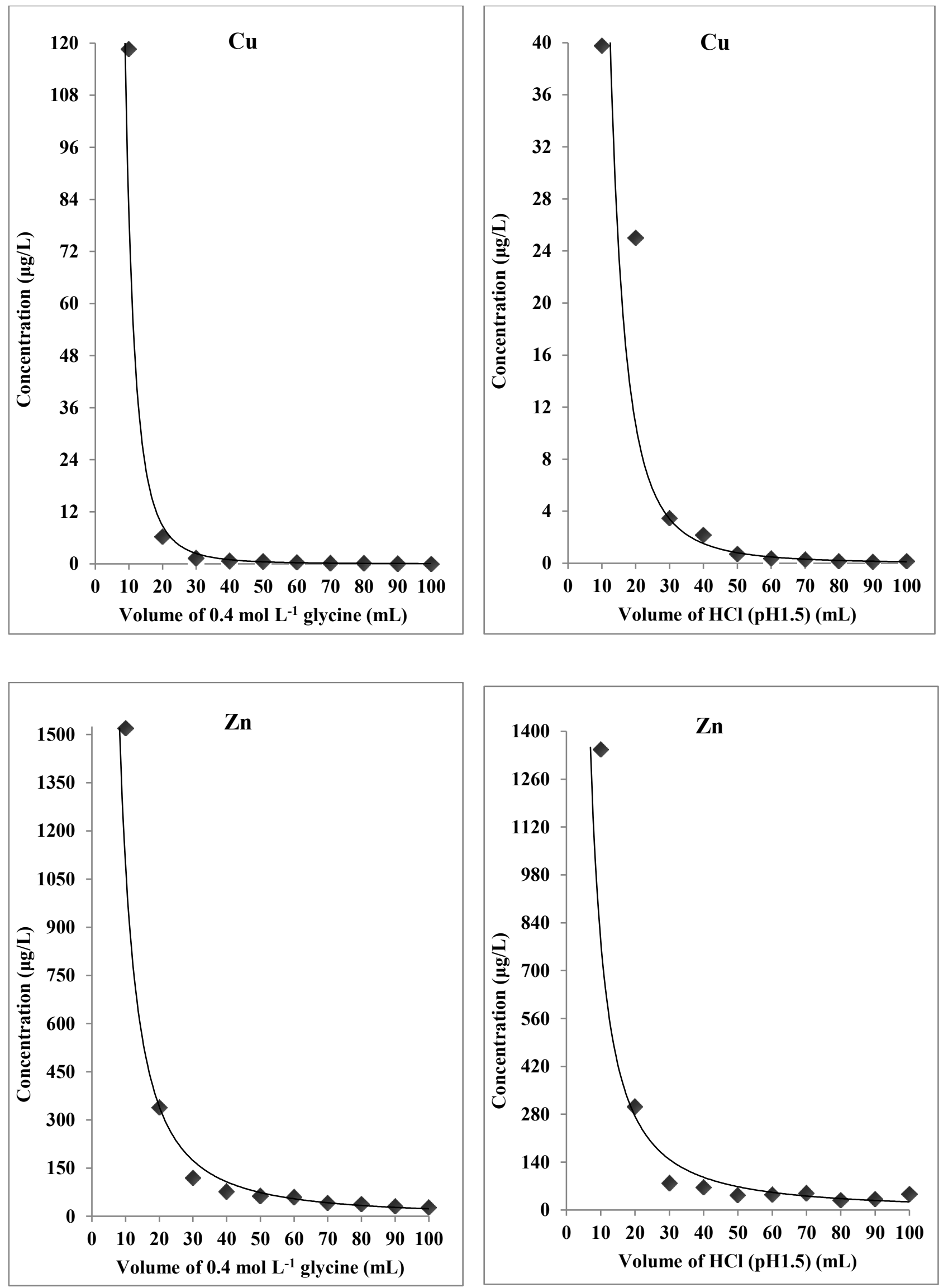

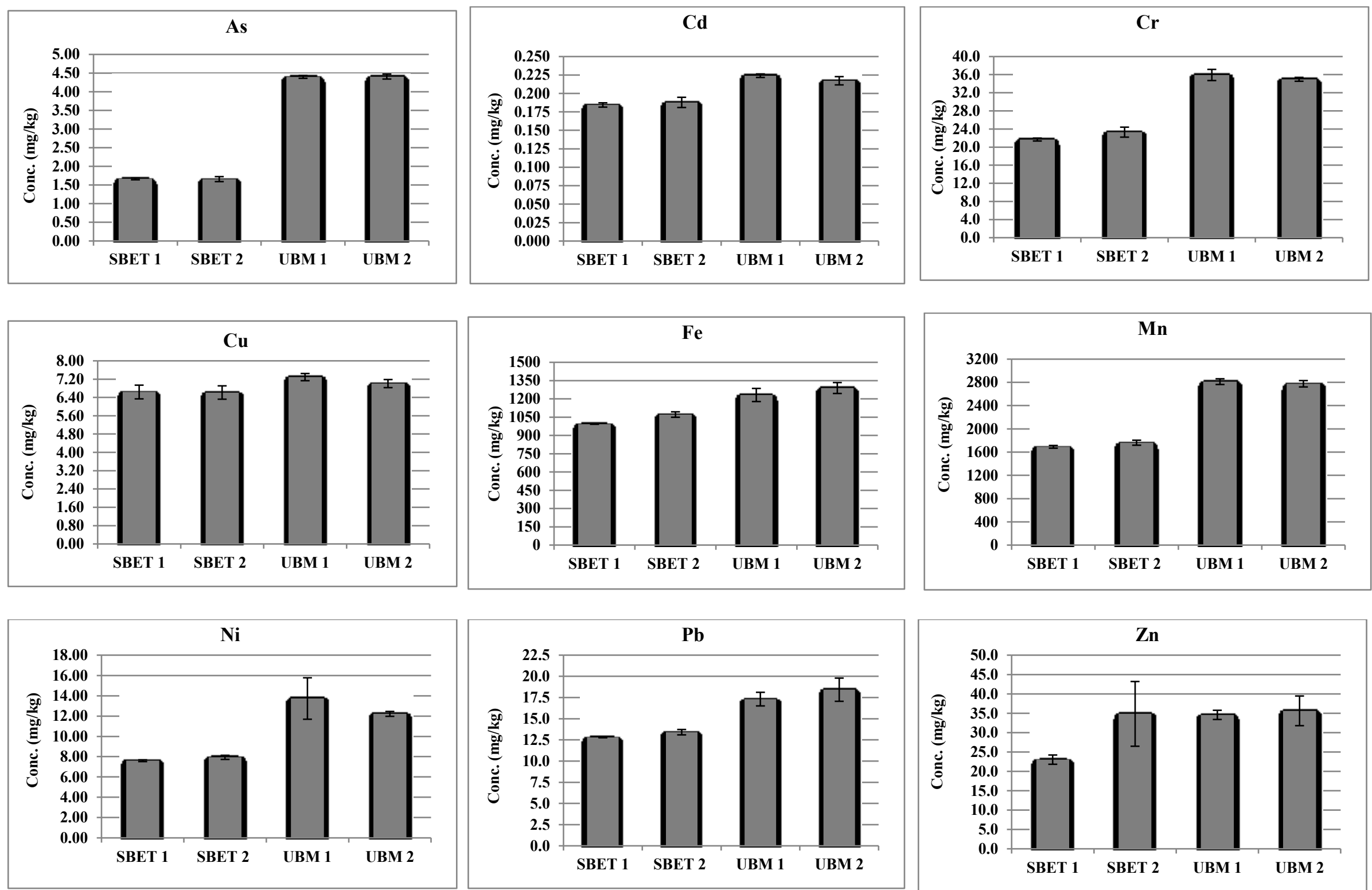
Table 1

Particle size distribution of Soil BGS102

Material

Mean particle diameter $(\mu \mathrm{m})$ d (0.5)

BGS102 (current study)

SRM 1648A Urban particulate matter (Certificate of Analysis)

SRM 2787 Fine particulate matter (Certificate of Analysis)

Data obtained using a Malvern Mastersizer 2000, d (0.5) indicates the particle size below which 50\% of the volume is present, $\mathrm{d}(0.1)$ indicates the particle size below which $10 \%$ of the volume is present, $d(0.9)$ indicates the particle size below which $90 \%$ of the volume is present
Particle diameter $(\mu \mathrm{m})$

d (0.1)

1.1

1.4

2.1

$\begin{array}{ll}7.6 & 1.1 \\ 5.8 & 1.4\end{array}$

Particle diameter $(\mu \mathrm{m})$

d (0.9)

43

30 
Table 2

ICP-MS operating conditions

\section{Power (W)}

Quadrupole bias (V)

Octopole bias (V)

Nebulizer gas flow $\left(\mathrm{L} \mathrm{min}^{-1}\right)$

Plasma gas flow $\left(\mathrm{L} \mathrm{min}^{-1}\right)$

Auxiliary gas flow $\left(\mathrm{L} \mathrm{min}^{-1}\right)$

Isotopes determined

Isotopes quantified (with internal standards in parenthesis)

Sample uptake rate $\left(\mathrm{mL} \min ^{-1}\right)$

\section{0}

$-15$

$-18$

0.85

15

0.9

${ }^{75} \mathrm{As},{ }^{111} \mathrm{Cd},{ }^{114} \mathrm{Cd},{ }^{52} \mathrm{Cr},{ }^{53} \mathrm{Cr},{ }^{63} \mathrm{Cu},{ }^{65} \mathrm{Cu},{ }^{56} \mathrm{Fe},{ }^{57} \mathrm{Fe},{ }^{55} \mathrm{Mn},{ }^{60} \mathrm{Ni},{ }^{61} \mathrm{Ni}$,

$$
{ }^{206} \mathrm{~Pb},{ }^{207} \mathrm{~Pb},{ }^{208} \mathrm{~Pb},{ }^{64} \mathrm{Zn} \text {, and }{ }^{66} \mathrm{Zn}
$$

${ }^{75} \mathrm{As}\left({ }^{72} \mathrm{Ge}\right),{ }^{111} \mathrm{Cd}\left({ }^{115} \mathrm{In}\right),{ }^{52} \mathrm{Cr}\left({ }^{45} \mathrm{Sc}\right),{ }^{63} \mathrm{Cu}\left({ }^{45} \mathrm{Sc}\right),{ }^{56} \mathrm{Fe}\left({ }^{45} \mathrm{Sc}\right),{ }^{55} \mathrm{Mn}\left({ }^{45} \mathrm{Sc}\right)$, ${ }^{60} \mathrm{Ni}\left({ }^{45} \mathrm{Sc}\right),{ }^{208} \mathrm{~Pb}\left({ }^{209} \mathrm{Bi}\right)$, and ${ }^{66} \mathrm{Zn}\left({ }^{72} \mathrm{Ge}\right)$ 
Table 3

Comparison between bioaccessible concentrations obtained by the original and the modified SBET and UBM (stomach phase) methods

\begin{tabular}{|c|c|c|c|c|c|c|c|c|}
\hline \multirow{3}{*}{ PTE } & \multicolumn{4}{|c|}{ Mean \pm SD $\left(\mathrm{mg} \mathrm{kg}^{-1}, \mathrm{n}=3\right)$} & \multicolumn{2}{|c|}{ Recovery (\%) } & \multicolumn{2}{|c|}{$\%$ RPD } \\
\hline & \multicolumn{2}{|c|}{ SBET } & \multicolumn{2}{|c|}{ UBM (stomach phase) } & \multirow{2}{*}{ SBET } & \multirow{2}{*}{$\begin{array}{c}\text { UBM } \\
\text { (stomach } \\
\text { phase) }\end{array}$} & \multirow{2}{*}{ SBET } & \multirow{2}{*}{$\begin{array}{c}\text { UBM } \\
\text { (stomach } \\
\text { phase) }\end{array}$} \\
\hline & Original & Miniaturized & Original & Miniaturized & & & & \\
\hline As & $2.31 \pm 0.20$ & $2.16 \pm 0.18$ & $4.88 \pm 0.04$ & $5.01 \pm 0.07$ & 93.8 & 103 & $6.44^{\mathrm{P}}$ & $2.54^{\mathrm{P}}$ \\
\hline Cd & $0.199 \pm 0.019$ & $0.196 \pm 0.020$ & $0.220 \pm 0.003$ & $0.214 \pm 0.004$ & 99 & 97.5 & $1.41^{\mathrm{P}}$ & $2.56^{\mathrm{P}}$ \\
\hline $\mathrm{Cr}$ & $23.8 \pm 1.8$ & $26.2 \pm 2.3$ & $37.7 \pm 0.4$ & $36.9 \pm 0.1$ & 110 & 97.8 & $9.68^{\mathrm{P}}$ & $2.21^{\mathrm{F}}$ \\
\hline $\mathbf{C u}$ & $7.30 \pm 0.78$ & $7.29 \pm 0.67$ & $7.91 \pm 0.04$ & $7.78 \pm 0.07$ & 99.9 & 98.4 & $0.138^{\mathrm{P}}$ & $1.59^{\mathrm{P}}$ \\
\hline $\mathrm{Fe}$ & $1130 \pm 91$ & $1350 \pm 123$ & $1490 \pm 30$ & $1560 \pm 42$ & 119 & 104 & $17.5^{\mathrm{P}}$ & $4.32^{\mathrm{P}}$ \\
\hline Mn & $2060 \pm 170$ & $1920 \pm 158$ & $3010 \pm 12$ & $2900 \pm 10$ & 93.3 & 96.3 & $6.98^{\mathrm{P}}$ & $3.82^{\mathrm{F}}$ \\
\hline $\mathbf{N i}$ & $8.61 \pm 0.69$ & $8.37 \pm 0.74$ & $12.5 \pm 0.1$ & $12.2 \pm 0.1$ & 97 & 97.6 & $2.74^{\mathrm{P}}$ & $2.46^{\mathrm{F}}$ \\
\hline $\mathbf{P b}$ & $15.1 \pm 1.4$ & $17.3 \pm 1.4$ & $19.5 \pm 0.5$ & $19.1 \pm 0.3$ & 115 & 97.8 & $13.7^{\mathrm{P}}$ & $2.22^{\mathrm{P}}$ \\
\hline $\mathrm{Zn}$ & $21.2 \pm 4.6$ & $20.2 \pm 15.8$ & $36.9 \pm 0.3$ & $35.7 \pm 0.4$ & 95 & 96.8 & $5.25^{\mathrm{P}}$ & $3.24^{\mathrm{F}}$ \\
\hline
\end{tabular}

n: number of replicates; Recovery (\%) $=$ ([mean measured value in the modified procedure]/[mean measured value in the original procedure]) $\times 100 ;$ RPD: Relative percent difference $=\{|a 1-a 2| /((a 1+a 2) / 2)\} \times 100$ where a1: values in the original procedure and a2: values in in the modified procedure; $P:$ means that t test (0.05 significance level) passed; $F$ : means that test failed 
Table 4

Bioaccessible concentrations of potentially toxic elements (PTE) in blank FDMS filters extracted using the modified simplified bioaccessibility extraction test (SBET) and the stomach phase of the unified bioaccessibility method (UBM)

\begin{tabular}{|c|c|c|c|c|}
\hline \multirow{2}{*}{ PTE } & \multicolumn{2}{|c|}{$\begin{array}{l}\text { SBET } \\
(n=3)\end{array}$} & \multicolumn{2}{|c|}{$\begin{array}{c}\text { UBM (stomach phase) } \\
((n=3)\end{array}$} \\
\hline & $\begin{array}{c}\mu g L^{-1} \\
\operatorname{Mean} \pm \mathrm{SD}\end{array}$ & $\begin{array}{l}\mu g \text { per filter } \\
\text { Mean } \pm \text { SD }\end{array}$ & $\begin{array}{c}\mu g \mathrm{~L}^{-1} \\
\text { Mean } \pm \mathrm{SD}\end{array}$ & $\begin{array}{l}\mu g \text { per filter } \\
\text { Mean } \pm \text { SD }\end{array}$ \\
\hline As & $<0.010$ & $<0.001$ & $<0.030$ & $<0.001$ \\
\hline Cd & $<0.003$ & $<0.001$ & $<0.005$ & $<0.001$ \\
\hline $\mathrm{Cr}$ & $0.100 \pm 0.060$ & $0.001 \pm 0.001$ & $<0.174$ & $<0.001$ \\
\hline $\mathrm{Cu}$ & $5.60 \pm 0.39$ & $0.056 \pm 0.004$ & $20.8 \pm 0.3$ & $0.078 \pm 0.001$ \\
\hline $\mathrm{Fe}$ & $<0.452$ & $<0.005$ & $<16.1$ & $<0.060$ \\
\hline Mn & $<0.134$ & $<0.001$ & $6.96 \pm 0.97$ & $0.026 \pm 0.004$ \\
\hline $\mathbf{N i}$ & $0.400 \pm 0.260$ & $0.004 \pm 0.003$ & $<0.137$ & $<0.001$ \\
\hline $\mathbf{P b}$ & $0.200 \pm 0.060$ & $0.002 \pm 0.001$ & $0.416 \pm 0.127$ & $0.002 \pm 0.001$ \\
\hline $\mathbf{Z n}$ & $284 \pm 53$ & $2.84 \pm 0.53$ & $986 \pm 88$ & $3.70 \pm 0.33$ \\
\hline
\end{tabular}


Table 5

$\mathrm{T}$ test and relative percent difference (RPD) of the bioaccessible concentrations of potentially toxic elements (PTE) in the simulated PM 10 (soil on FDMS filters) and in soil alone using the simplified bioaccessibility extraction test (SBET) and the stomach phase of the unified bioaccessibility method (UBM)

\begin{tabular}{|c|c|c|c|c|c|c|}
\hline \multirow{3}{*}{ PTE } & \multicolumn{4}{|c|}{ T test (between soil alone and soil on FDMS filters) } & \multirow{2}{*}{\multicolumn{2}{|c|}{$\%$ RPD }} \\
\hline & \multicolumn{2}{|c|}{ SBET $\left(v=4^{a}, 2^{b}\right)$} & \multicolumn{2}{|c|}{ UBM (stomach phase) $\left(v=4^{a}, 2^{b}\right)$} & & \\
\hline & t calculated & t critical & t calculated & t critical & SBET & $\begin{array}{c}\text { UBM (stomach } \\
\text { phase) }\end{array}$ \\
\hline As & 0.24 & $2.78^{\mathrm{a}}$ & 0.24 & $2.78^{\mathrm{a}}$ & 0.108 & 0.216 \\
\hline Cd & 0.91 & $2.78^{\mathrm{a}}$ & 0.91 & $2.78^{\mathrm{a}}$ & 0.467 & 3.10 \\
\hline $\mathrm{Cr}$ & 2.42 & $2.78^{\mathrm{a}}$ & 2.42 & $2.78^{\mathrm{a}}$ & 1.82 & 2.72 \\
\hline $\mathbf{C u}$ & 0.08 & $2.78^{\mathrm{a}}$ & 0.08 & $2.78^{\mathrm{a}}$ & 0.083 & 3.97 \\
\hline $\mathbf{F e}$ & 6.01 & $4.30^{\mathrm{b}}$ & 6.01 & $4.30^{\mathrm{b}}$ & 1.90 & 4.53 \\
\hline Mn & 2.51 & $2.78^{\mathrm{a}}$ & 2.51 & $2.78^{\mathrm{a}}$ & 1.03 & 1.31 \\
\hline $\mathbf{N i}$ & 2.60 & $2.78^{\mathrm{a}}$ & 2.60 & $2.78^{\mathrm{a}}$ & 1.07 & 11.7 \\
\hline $\mathbf{P b}$ & 3.25 & $4.30^{\mathrm{b}}$ & 3.25 & $4.30^{\mathrm{b}}$ & 1.17 & 6.20 \\
\hline $\mathrm{Zn}$ & 2.42 & $4.30^{\mathrm{b}}$ & 2.42 & $4.30^{\mathrm{b}}$ & 10.2 & 2.98 \\
\hline
\end{tabular}

loaded on FDMS filter 